Research Journal of Applied Sciences 5 (2): 126-130, 2010

ISSN: $1815-932 \mathrm{X}$

(C) Medwell Journals, 2010

\title{
Lineament Mapping Using Multispectral Remote Sensing Satellite Data
}

\author{
Maged Marghany and Mazlan Hashim \\ Institute of Geospatial Science and Technology (INSTEG), \\ University of Teknologi, Malaysia
}

\begin{abstract}
Accurate geological features mapping is critical task for oil exploration, groundwater storage and understanding the mechanisms of environmental disasters e.g., earthquake, flood and landslides. The main objective of this research is to design an automatic image processing tool for lineament mapping from remote sensing satellite data. In doing so, LANDSAT-TM satellite data of United Arab Emirates (UAE) is used. Further, three dimensional (3D) image reconstruction is generated using SRTM data. Then Canny algorithms is examined to determine an appropriate algorithm for lineaments automatic detection in LANDSAT-TM satellite data. The study shows that Canny algorithm provides perfect information about lineaments with 3D image visualization which is derived using SRTM. In conclusion 3D image visualization can provide excellent information about lineament and geological features from remote sensing satellite data.
\end{abstract}

Key words: LANDSAT-TM satellite data, lineament, Canny algorithm, STRM, 3D image, Malaysia

\section{INTRODUCTION}

The major task of geologists is documentation of temporal and spatial variations in the distribution and abundance of geological features over wide scale. In this context, the major challenge is that most of conventional geological surveying techniques are not able to cover a wide region of such as desert in the Earth's surface. Quite clearly to understand the mechanisms generations of geological features and their relationship with environmental disasters such as earthquake, landslide and flood, geological researchers must be able to conduct simultaneous measurements over broad areas of surface or subsurface of the Earth (Marghany et al., 2009). This requires the collection of asset of reliable synoptic data that specify variations of critical geological environmental parameters over a wide region for discrete moments (Maged and Mazlan, 2008). In fact that geological features such as lineament and faults are key parameters that described the Earth generation or disaster mechanisms and significant indicator for oil explorations and groundwater storages (Semere and Ghebreab, 2006).

Fortunately, the application of remote-sensing technology from space is providing geologists with means of acquiring these synoptic data sets. Consequently, optical remote sensing techniques over more than three decades have shown a great promise for mapping geological feature variations over wide scale (Semere and Ghebreab, 2006; Maged and Mazlan, 2008; Marghany et al., 2009). In referring to Katsuaki et al. (1995), Moore et al. (1998) and Walsh (2000) lineament information extractions in satellite images can be divided broadly into three categories: lineament enhancement and lineament extraction for characterization of geologic structure; image classification to perform geologic mapping or to locate spectrally anomalous zones attributable to mineralization (Mostafa and Qari, 1995; Suzen and Toprak, 1998) and superposition of satellite images and multiple data such as geological, geochemical and geophysical data in a geographical information system (Novak and Soulakellis, 2000; Semere and Ghebreab, 2006).

Furthermore, remote sensing data assimilation in real time could be a bulk tool for geological features extraction and mapping. In this context, several investigations currently underway on the assimilation of both passive and active remotely sensed data into automatic detection of significant geological features i.e., lineament. Edge automatic detection algorithms such as Laplacian, Sobel and Canny are the major image processing tool for lineament features detection in remotely sensed data. In this study there is integration of different automatic detection algorithms to develop a new approach for lineament detection and mapping.

\section{MATERIALS AND METHODS}

Study area: The study area is located in Sharjah Emirates about $70 \mathrm{~km}$ from Sharjah city. It is considered in the alluvium plain for central area of UAE and covers an Area of $1800 \mathrm{Km}^{2}(60 \times 30 \mathrm{~km})$ within boundaries of latitudes $24^{\circ}$ $12 \mathrm{~N}-24^{\circ} .23^{\prime} \mathrm{N}$ and longitudes of $55^{\circ} .51^{\prime} \mathrm{E}-55^{\circ} 59^{\prime} \mathrm{E}$ (Fig. 1). The northern part of UAE is formed of the Oman mountains and the marginal hills extends from the

Corresponding Author: Maged Marghany, Institute of Geospatial Science and Technology (INSTEG), University of Teknologi, Malaysia 


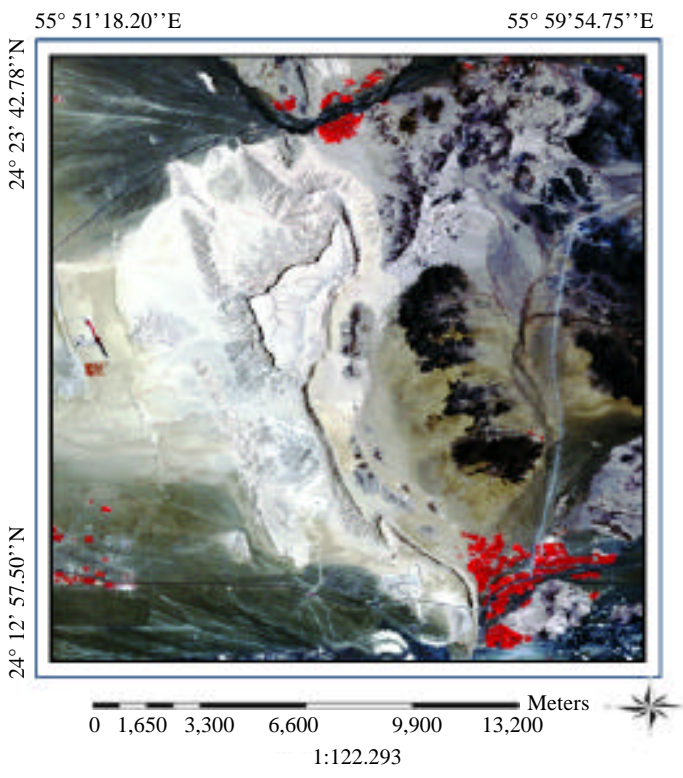

Fig. 1: Location of study area

base of the mountains and (alluvium plain) to the south western sand dunes. Land geomorphology is consisted of structural form, fluvial and Aeolian forms (sand dunes). According to Marghany et al. (2009) structural form is broad of the Oman mountains and Jabal Fayah which are folded structure due collusion of oceanic crust and Arabian plate (continental plate).

Furthermore, the mountain is raised higher than 400 $\mathrm{m}$ above sea level and exhibit parallel ridges and hightilted beds. Many valleys are cut down the mountains forming narrow clefts and there are also intermittent basins caused by differential erosion. In addition, the valley bases are formed small caves.

Data set: The satellite data are used in this study acquired from LANDSAT-TM which covered an area located between latitudes $24^{\circ} 12^{\prime} \mathrm{N}-24^{\circ} .23^{\prime} \mathrm{N}$ and longitudes of $55^{\circ} .51-55^{\circ} 59^{\prime} \mathrm{E}$ (Fig. 1). Bands 1, 2, 3, 5 and 7 are selected to achieve the objective of this study. According to Marghany et al. (2009) these bands can provide accurate geological information. Finally, the Digital Elevation Model (DEM) is acquired from SRTM data.

Lineament extraction procedures: This section describes the procedures have been used to extract lineaments pattern from LANDSAT TM satellite images. Following (Maged and Mazlan, 2008) image enhancement contrast, stretching and linear enhancement are applied to acquire an excellent visualization. In addition, automatic detection algorithm of Canny then is to acquire lineament mapping (Fig. 2).

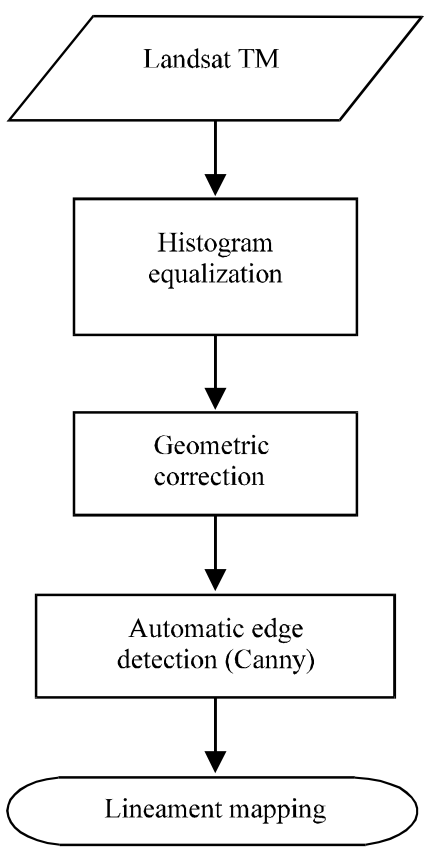

Fig. 2: Flow chart of lineament mapping from LANDSATTM satellite data

Histogram equalization: Following Maged and Mazlan (2008) and Marghany et al. (2009) histogram equalization is applied to LANDSAT-TM image to obtain high quality image visualization. An image histogram is an analytic tool used to measure the amplitude distribution of pixels within an image. For example, a histogram can be used to provide a count of the number of pixels at amplitude 0 , the number at amplitude 1 and so on. By analyzing the distribution of pixel amplitudes, you can gain some information about the visual appearance of an image. A high-contrast image contains a wide distribution of pixel counts covering the entire amplitude range. A low contrast image has most of the pixel amplitudes congregated in a relatively narrow range (Gonzalez and Woods, 1992).

Canny algorithm procedures: According to Canny (1986), the Canny edge detector uses a filter based on the first derivative of a Gaussian because it is susceptible to noise present on raw unprocessed image data so to begin with the raw image is convolved with a Gaussian filter. The result is a slightly blurred version of the original which is not affected by a single noisy pixel to any significant degree. According to Deriche (1987) the edge detection operator (Roberts, Prewitt, Sobel) returns a value for the first derivative in the horizontal direction $\left(\mathrm{G}_{\mathrm{y}}\right)$ and the vertical direction $\left(G_{\mathrm{z}}\right)$. From this the edge gradient and direction $(\theta)$ can be determined: 


$$
\begin{aligned}
& \mathrm{G}=\sqrt{\mathrm{G}_{\mathrm{X}}^{2}}+\mathrm{G}_{\mathrm{Y}}^{2} \\
& \theta=\arctan \left(\frac{\mathrm{G}_{\mathrm{Y}}}{\mathrm{G}_{\mathrm{X}}}\right)
\end{aligned}
$$

According to Gonzalez and Woods (1992), three criteria are used to improve edge detection. The first and most obvious is low error rate. It is important that edges occurring in images should not be missed and that there be NO responses to non-edges. The second criterion is that the edge points be well localized. In other words, the distance between the edge pixels as found by the detector and the actual edge is to be at a minimum. A third criterion is to have only one response to a single edge. This was implemented because the first 2 were not substantial enough to completely eliminate the possibility of multiple responses to an edge (Canny, 1986).

\section{RESULTS AND DISCUSSION}

Digital Elevation Model (DEM) is derived from SRTM data is shown in Fig. 3. It is clear that DEM varies between 319-929 m. Maximum elevation is found in northeast direction of UAE. It is clear that area adjacent to the mountainous area from Manamh (northward), Flili village in the (southward) has high density of lineaments due to the westward compressive force between the oceanic crust and Arabian plate such as fractures and faults and drainage pattern that running in the buried fault plains (filled weathered materials coming from Oman mountains) (Maged and Mazlan, 2008;
Marghany et al., 2009). Figure 4 shows the supervised classification map of LANDSAT-TM satellite data. It clears that the vegetation covers are located in highest elevation as integrated with Fig. 3 while highlands are located in lowest elevation. The supervised classification shows a great fault moves through a highland area.

Figure 5 shows the output result mapping of lineaments using composite of bands $3,4,5$ and 7 in LANDSAT-TM satellite data. The appearance of lineaments in LANDSAT-TM satellite image are clearly distinguished. The lineaments are associated with fractures and faults which are located in northern part of Fig. 5. In fact that Canny algorithm first smoothes the image to eliminate and noise. It then finds the image gradient to highlight regions with high spatial derivatives. The algorithm then tracks along these regions and suppresses any pixel that is not at the maximum (non-maximum suppression).

The gradient array is further reduced by hysteresis. According to Deriche (1987), hysteresis is used to track along the remaining pixels that have not been suppressed. Hysteresis uses two thresholds and if the magnitude is below the first threshold, it is set to zero (made a nonedge).

Further, If the magnitude is above the high threshold, it is made an edge and if the magnitude is between the 2 thresholds then it is set to zero unless there is a path from this pixel to a pixel with a gradient above threshold. In order to implement the canny edge detector algorithm, a series of steps must be followed. The first step is to filter out any noise in the original image before trying to locate and detect any edges. In fact, the

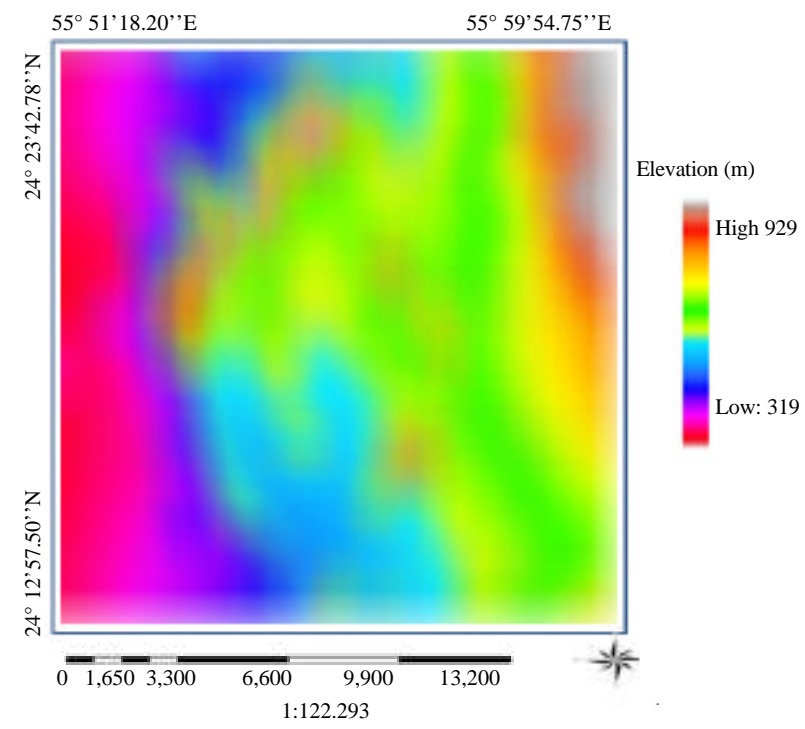

Fig. 3: DEM for study area 


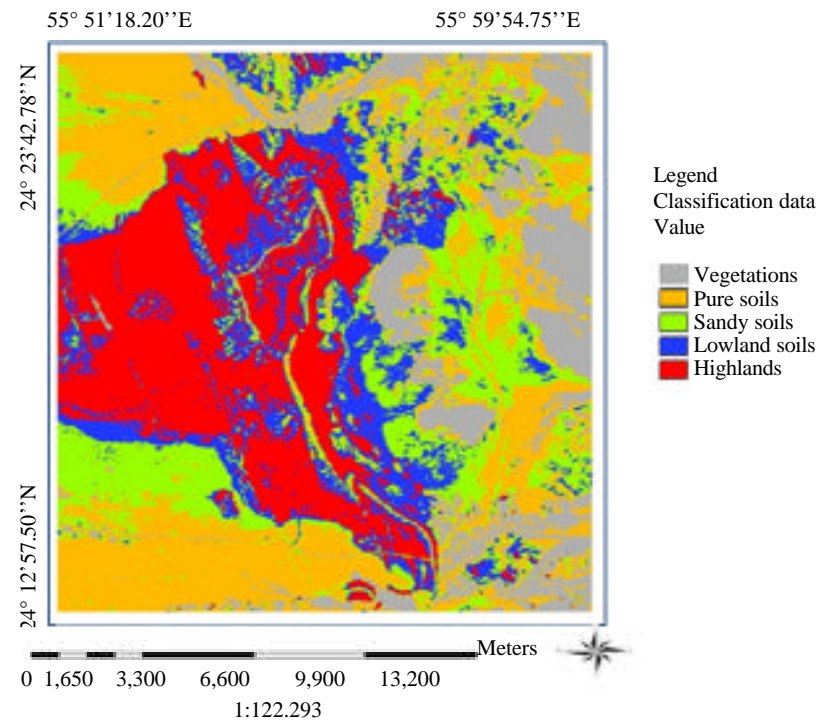

Fig. 4: Supervised map results

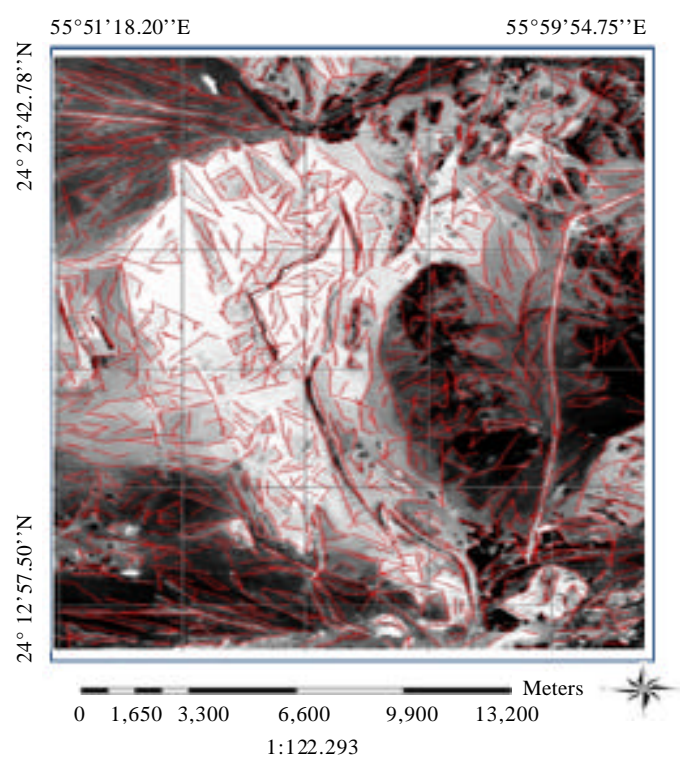

Fig. 5: Lineament mapping using Canny algorithm

Gaussian filter can be computed using a simple mask, it is used exclusively in the Canny algorithm. Once a suitable mask has been calculated, the Gaussian smoothing can be performed using standard convolution methods.

According to Marghany et al. (2009), LANDSAT-TM data can be used to map geological features such as lineaments and faults. This could be contributed to that composite of bands 3, 4, 5 able and 7 in LANDSAT-TM satellite data are appropriate for mapping of geologic structures (Katsuaki et al., 1995; Novak and Soulakellis 2000; Maged and Mazlan, 2008; Marghany et al., 2009). Consequently, the ground resolution cell size of

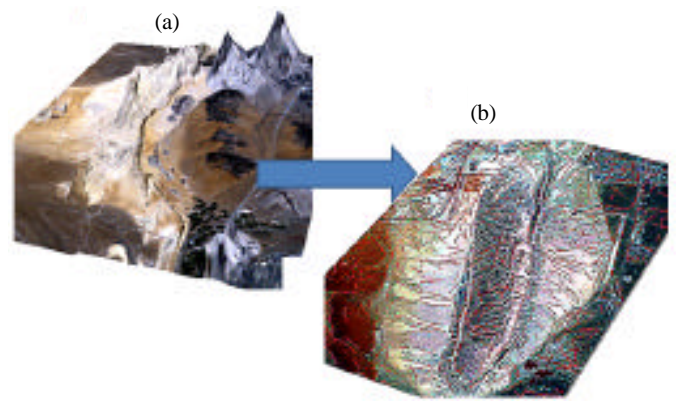

Fig. 6: (a) 3D image reconstruction using SRTM data and (b) lineament distribution over 3D image

LANDSAT TM data is about $30 \mathrm{~m}$. Figure 6 shows the lineament distribution with 3D map reconstruction using SRTM and LANDSAT TM bands 3, 4, 5 and 7. It is clear that the $3 \mathrm{D}$ visualization discriminates between different geological features. It can be noticed the faults, lineament and infrastructures clearly (Fig. 6b). This study agrees with Marghany et al. (2009).

It can be confirmed that the lineament are associated with faults and it also obvious that heavy capacity of lineament occurrences within the Oman mountain. This type of lineament can be named as mountain lineament.

According to Marghany et al. (2009) the mountain is raised higher than $400 \mathrm{~m}$ above sea level and exhibit parallel ridges and high-tilted beds. Many valleys are cut down the mountains, forming narrow clefts and small caves. The fluvial forms are consisted of streams channels which are flowed from Oman mountains have and spread out into several braided channels at the base of the mountains from the Bahada and Playa plains (Fig. 7). 


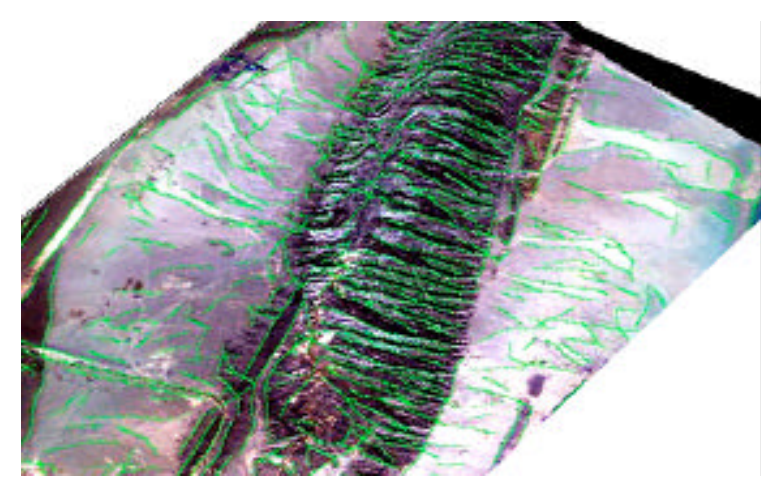

Fig. 7: 3D image and lineament distribution from Canny algorithm

Stream channels have been diverted to the southwest and they deposited silt in the tongue-shaped which lies between the dunes.

Further, Aeolian forms are extended westwards from the Bahada plain where liner dunes run towards the southwest direction in parallel branching pattern (Fig. 3) with relative heights of $50 \mathrm{~m}$. Nevertheless, the heights are decreased towards the southeast due to a decrease in sand supply and erosion caused by water occasionally flowing from the Oman mountains.

Moreover, some of the linear dunes are quite complex due to the development of rows of star dunes along the top of their axes. Additionally, inter dunes areas are covered by fluvial material which are laid down in the playas formed at the margins of the Bahadas plain near the coastline. The dunes changes their forms to low flats of marine origin and their components are also dominated by bioclastics and quartz sands (Marghany et al., 2009).

\section{CONCLUSION}

This study has demonstrated a method to map lineament distributions in United Arab Emirates (UAE) using LANDSAT-TM satellite data. In doing so, 3D image reconstruction is produced using SRTM data and then Canny algorithm is implemented for lineament automatic detection from LANDSAT-TM bands of 3, 4, 5 and 7. It can be said that the integration between Digital Elevation Model (DEM) and Canny algorithm can be used as automatic detection and visual tool for lineament mapping.

\section{REFERENCES}

Canny, J., 1986. A computational approach to edge detection. IEEE Trans. Patt. Anal. Mach. Intel., 8: 679-698.

Deriche, R., 1987. Using canny's criteria to derive an optimal edge detector recursively implemented. Int. J. Comput., 1: 167-187.

Gonzalez, R.C. and R.E. Woods, 1992. Digital Image Processing. Addison-Wesley, Reading, MA.

Katsuaki, K., N. Shuichi and M. Ohmi, 1995. Lineament analysis of satellite images using a segment tracing algorithm (STA). Comput. Geosciences, 21: 1091-1104.

Maged, M. and H. Mazlan, 2008. 3D lineament reconstruction from multispectral remotely sensed data in united Arab Emirate (UAE). CD. Proceedings of The 29th Asian Conference on Remote Sensing, Nov. 10-14, Colombo, Sri Lanka, pp: 1-8.

Marghany, M., M.Hashim and S. Mansor, 2009. Geologic mapping of united arab emirates using multispectral remotely sensed data. Am. J. Eng. Applied Sci., 2: 476-480.

Moore, R.B., S.F. Clark Jr., E.W. Ferguson, G.J. Marcoux and J.R. Degnan, 1998. New hampshire bedrock aquifer assessment: Correlating yields from 18,000 wells with geologic features. Proceeding of the Conference on Northeast Focus Ground Water, Oct. 20-21, National Ground Water Association, Burlington, Vt., pp: 18-18.

Mostafa, M.E. and M.Y.H.T. Qari, 1995. An exact technique of counting lineaments. Eng. Geol., 33: $78-78$.

Novak, I.D. and N. Soulakellis, 2000. Identifying geomorphic features using Landsat-5/TM data processing techniques on lesvos, Greece. Geomorphology, 34: 101-109.

Semere, S. and W. Ghebreab, 2006. Lineament characterization and their tectonic significance using Landsat TM data and field studies in the central highlands of Eritrea. J. Afr. Earth Sci., 46: 371-378.

Suzen, M.L. and V. Toprak, 1998. Filtering of satellite images in geological lineament analyses: An application to a fault zone in Central Turkey. Int. J. Remote Sensing, 19: 1101-1114.

Walsh, G.J., 2000. Geologic controls on remotely sensed lineaments in Southeastern New Hampshire. Abst. Prog. Northeast. Sect. Geol. Soc. Am., 32: 81-81. 